\title{
Development of hardened PVF : PMMA polyblend: effect of gamma and electron irradiation
}

\author{
R BAJPAI*, N B DHAGAT $T^{\dagger}$, R KATARE , PRAGYESH AGRAWAL $^{\ddagger}$ and S C DATT \\ Department of PG Studies and Research in Physics, Rani Durgavati University, Jabalpur 482 001, India \\ ${ }^{\dagger}$ Department of Physics, Govt. Autonomous Science College, Jabalpur 482 001, India \\ ${ }^{*}$ Department of Physics, St. Aloysius College, Jabalpur 482 001, India
}

MS received 10 June 2002; revised 6 March 2003

\begin{abstract}
Specimens of poly(vinyl formal) (PVF) : poly(methyl methacrylate) (PMMA) polyblends with different weight percentage ratios were subjected to gamma irradiation ( 1 to 50 Mrad) and electron irradiation ( 1 to $20 \mathrm{Mrad}$ ). The effect of irradiation on the strength of the blend specimens was studied by measuring the surface microhardness using a Vickers microhardness tester attached to a Carl Zeiss NU 2 Universal research microscope. Significant changes were observed in the Vickers microhardness number, $H_{v}$. The $H_{v}$ values of gamma irradiated specimens are found to be higher than the unirradiated specimens indicating an occurrence of radiational crosslinking. The maximum value of $H_{v}$ is obtained at the gamma radiation dose of $15 \mathrm{Mrad}$. In case of electron irradiation the radiational crosslinking is found to take place for the blend specimens having lower wt\% content of PMMA (0 and 1 wt\%) in PVF matrix. On the other hand degradation of polymeric system is observed for the blends having PMMA content more than 1 wt\%. The maximum value of $H_{v}$ is obtained for all the blend specimens at the electron irradiation dose of $8 \mathrm{Mrad}$. The degree of crosslinking in polyblends due to gamma irradiation is found to be more than electron irradiation. The scissioning mechanism is found to predominate in the polyblend system in case of electron irradiation.
\end{abstract}

Keywords. Polyblend; microhardness; irradiation; crosslinking; degradation.

\section{Introduction}

The modification of polymers by radiation, either to crosslink or to break molecules, is a significant industrial process throughout the world. Extensive studies have been undertaken to understand this technology and the effects of radiation on the most significant classes of polymers are reasonably well catalogued and understood (Charlesby 1954; Sisman and Bopp 1954; Bopp and Sisman 1955; Bajpai et al 1994; Nagesh et al 1999). Many widely used polymers suffer main chain scission and a loss in mechanical strength (Hu et al 1999); such polymers are known as the degrading polymers. On the other hand, many polymers are found to possess enhanced molecular ordering after being irradiated (McCarthy and Mark 1998). Degradation and crosslinking both could be the consequences of irradiation. Depending on the conditions of irradiation and the chemical structure of the polymer, either crosslinking or degradation occurs and the one which predominates determines the net effect (Bradley et al 1984). The size, shape and chemical nature of the polymeric macromolecules also determine the degree

*Author for correspondence of these two phenomena. It is possible to produce fluorocarbon-like low surface energy polymers by the addition of small amounts of selected additives to nonfluorinated polymers such as poly(vinylidene chloride), poly(methyl methacrylate) (PMMA) and polyacrylamide (Jarvis et al 1964).

Further, the polymer blends are being studied these days because of the possible improvement in physical properties of the mixture incorporating the individual properties of polymers (Hermes and Higgins 1998; Bajpai et al 2002). Polyvinylformal (PVF) is a linear polymer belonging to polyvinyl acetal (PVA) group. Since PVF is a derivative of PVA the blends of PVA can be developed with PVF. PMMA also exhibits miscibility with PVA. Moreover, PMMA is a versatile polymer with wide commercial applications exhibiting good mechanical properties and outdoor weathering. Therefore, the PVF : PMMA polyblends have been developed with various weight proportions of these two polymers. The present paper reports the study on the surface modification of gamma and electron irradiated PVF : PMMA blend system. The tool used for detection is Vickers microhardness technique. This technique is now being widely used for morphological stabilization and plasticization studies on polymers (Gonzalez et al 1986; Pandey et al 1990; Bajpai et al 1992; Mishra et al 1994). 


\section{Experimental}

The solution cast technique (Agrawal et al 1996) has been utilized for preparing the blends of PVF and PMMA. Polymer granules of PVF and PMMA of low molecular weight grade (BDH, England) were supplied by M/s Chemical Agencies, Mumbai. The glass transition temperature of both PVF and PMMA is $105^{\circ} \mathrm{C}$. The two polymers in selected weight proportions were dissolved in mixture of benzene : ethanol $(3: 2)$ at $40^{\circ} \mathrm{C}$. The solution was poured in glass moulds and solvent was evaporated at $40^{\circ} \mathrm{C}$ to yield specimens of size $1 \times 1 \mathrm{sq} \mathrm{cm}$ and $1 \mathrm{~mm}$ thickness.

\subsection{Gamma irradiation}

The gamma irradiation of the square shaped, $1 \mathrm{~mm}$ thick, specimens was carried out at the University Science Instrumentation Centre (USIC), Nagpur University, Nagpur. "Co 60 Gamma Chamber-900" was used as the irradiation source. Samples were irradiated with various doses ranging from 1 to $50 \mathrm{Mrad}(1,3,5,10,15,20,25$, 30 and $50 \mathrm{Mrad}$ ). The average irradiation dose rate was $0.35 \mathrm{Mrad} / \mathrm{h}$.

\subsection{Electron irradiation}

The electron irradiation of the specimens was carried out at the Isotope Division of Bhabha Atomic Research Centre (BARC), Mumbai. An Industrial Electron Accelerator (ILU-6- $\mathrm{M}_{3}$ type), with an electron beam of energy of $2 \mathrm{MeV}$ was used as the radiation source. The average dose delivered was $5 \mathrm{Mrad}$ when 3,250 pulses were given at a pulse rate of 10 pulses/s.

\subsection{Analytical procedure}

The irradiated specimens were indented at room temperature by a mhp-160 microhardness tester with a Vickers diamond pyramid indenter having a square base and $136^{\circ}$ pyramid angle, attached to a Carl Zeiss NU 2 Universal research microscope. The indenting load ranged from 60 to $100 \mathrm{~g}$. This was the saturation load range for the blends at the concentration ratios under examination. The diameters of indentation were measured by a micrometer eyepiece with an objective of magnification $(12.5 \times)$. The Vickers hardness number, $H_{\mathrm{v}}$, was calculated from the relation

$$
H_{\mathrm{v}}=1.854 L / d^{2}\left(\mathrm{~kg} / \mathrm{mm}^{2}\right),
$$

where $L$ is load $(\mathrm{kg})$ and $d$ the diameter of indentation $(\mathrm{mm})$. For each test the duration of indentation was $30 \mathrm{~s}$. For each load at least five indentations were made at different points of the specimen, and the average $H_{\mathrm{v}}$ was computed. During the test the specimens were kept strictly horizontal and rigid.

\section{Results and discussion}

\subsection{Effect of composition}

Figure 1 depicts the variation of Vickers microhardness number, $H_{\mathrm{v}}$, with various weight percentages of PMMA in the blends of PVF : PMMA at a saturation load of $80 \mathrm{~g}$. It is seen that $H_{\mathrm{v}}$ gradually increases with increasing content of PMMA in the range of 1 to $7 \mathrm{wt} \%$. The value of $H_{\mathrm{v}}$ increases with increasing value of load up to $80 \mathrm{~g}$. The graph is plotted using the load of $80 \mathrm{~g}$ as at and beyond this value of load the microhardness of the specimen becomes independent of load and attains a level of saturation. The increasing PMMA content in this polymeric system causes an increase in stiffness, i.e. PMMA up to $7 \mathrm{wt} \%$ toughens the blends as depicted by the increase in the value of $H_{v}$. All the polyblends studied have higher $H_{\mathrm{v}}$ values than the pure PVF. Further, the blends in pellet form were clear and transparent. This indicates the miscibility of PVF and PMMA in the selected composition ratios. The miscibility of the two polymers in the blend can also be detected from the microhardness measurements, as the value of $H_{\mathrm{v}}$ of blend increases with increase in content of PMMA in the blend up to $7 \mathrm{wt} \%$ indicating progressive mixing of PMMA in PVF.

PMMA which has higher mechanical strength as compared to pure PVF, imparts mechanical strength to PVF. The polyblend so formed has increased microhardness and thus hardened PVF: PMMA polyblends are produced. Thus, the two polymers are also mechanically compatible as revealed from microhardness studies up to the blending ratio of $93: 7$ (PVF : PMMA). Addition of PMMA up to $7 \mathrm{wt} \%$ develops crosslinks with PVF molecules, thus

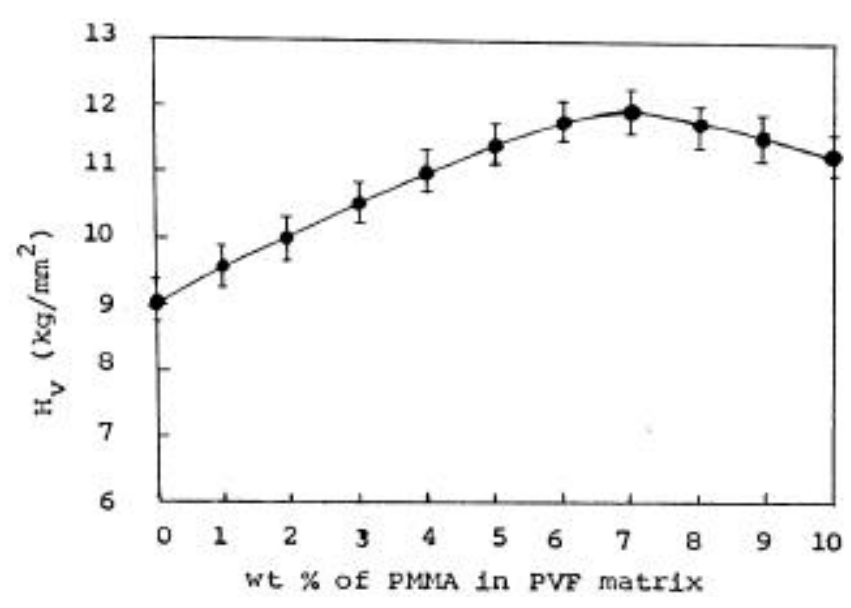

Figure 1. Variation of $H_{\mathrm{v}}$ with different wt $\%$ of PMMA in PVF : PMMA polyblend specimens at the saturation load of $80 \mathrm{~g}$. 
resulting in hardened blends. Addition of PMMA beyond $7 \mathrm{wt} \%$ in the blend tends to slightly decrease the $H_{\mathrm{v}}$ value at different loads. However, this effect tends to get stabilized beyond $8 \mathrm{wt} \%$ and up to $10 \mathrm{wt} \%$ of PMMA in the blend, thus increasing PMMA beyond $7 \mathrm{wt} \%$ slightly softens the blend. This indicates that the miscibility of two polymers above this composition range decreases and slightly phase separated systems are developed exhibiting decreased value of $H_{\mathrm{v}}$. Moreover, this effect is slightly observed only up to $10 \mathrm{wt} \%$ of PMMA in the blend. Hence, the optimum desired ratio of PVF : PMMA for toughened blends is $93: 7$. PMMA acts as hardener to $\mathrm{PVF}$ in this composition range.

\subsection{Effect of gamma irradiation}

Figure 2 exhibits the effect of various doses of gamma radiation ranging from 0 to $50 \mathrm{Mrad}$ on the surface microhardness of pure PVF and PVF : PMMA polyblends at the saturation load of $60 \mathrm{~g}$. It is observed that the $H_{\mathrm{v}}$ values for both pure PVF and polyblends are higher than the corresponding $H_{\mathrm{v}}$ values of the unirradiated $(0 \mathrm{Mrad})$

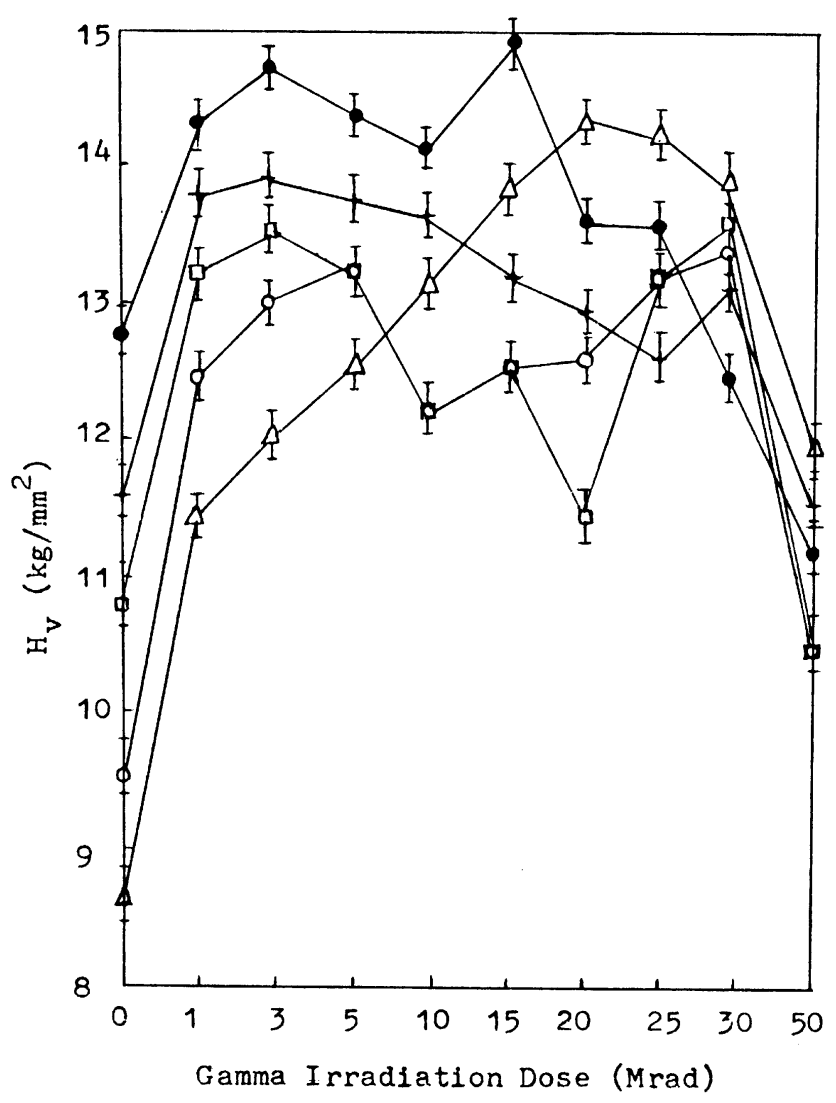

Figure 2. Variation of $H_{\mathrm{v}}$ with various doses of gamma irradiation at a saturation load of $60 \mathrm{~g}$ for pure PVF and blend specimens of PVF : PMMA with different weight percentage ratios $(\Delta, 100: 0 ; 0,99: 1 ; \square, 97: 3 ;+, 95: 5$ and $\bullet, 93: 7)$. specimens. This clearly indicates an overall hardening of specimens when exposed to gamma irradiation which imparts radiational crosslinking. However, increasing and decreasing nature of $H_{\mathrm{v}}$ with increasing dose beyond $1 \mathrm{Mrad}$ is obtained for all the specimens. These $H_{\mathrm{v}}$ values of the irradiated specimens are still higher than the unirradiated specimens. For pure PVF specimens, the value of $H_{\mathrm{v}}$ increases with dose in the range of 0 to $30 \mathrm{Mrad}$. This increasing microhardness of pure PVF with gamma irradiation induces crosslinking in PVF which is otherwise soft polymer. The gradual increase in crosslinking with irradiation suggests increase in molecular ordering of PVF. This radiational effect on PVF is maximum at the dose level of $20 \mathrm{Mrad}$, which then saturates up to $30 \mathrm{Mrad}$. Beyond $30 \mathrm{Mrad}$, the value of $H_{\mathrm{v}}$ decreases up to the dose of $50 \mathrm{Mrad}$. This decrease at a higher dose of irradiation indicates the degradation due to scissioning which destroys crosslinking density. However, the extent of this degradation at $50 \mathrm{Mrad}$ is only with respect to the irradiated PVF specimens and not with respect to the unirradiated pure PVF.

Considering the effect of gamma irradiation on the microhardness of PVF : PMMA polyblends, it is evident that out of the four polyblends $(99: 1,97: 3,95: 5$ and $93: 7)$ shown in figure 1 the polyblends with 1 and $3 \mathrm{wt} \%$ PMMA exhibit higher $H_{\mathrm{v}}$ values up to the dose of $5 \mathrm{Mrad}$ as compared to pure PVF, whereas polyblends with 5 and $7 \mathrm{wt} \%$ PMMA show this increased microhardness level when irradiated up to the dose level of 10 and $15 \mathrm{Mrad}$, respectively. Analysing the increasing and decreasing profiles of the irradiated polyblends, it can be observed that in all the polyblends, the value of microhardness fluctuates with the varying radiation dosage. This variation of microhardness can be explained with the help of formation of radiational crosslinks and scissioning phenomenon.

The toughening character of PVF : PMMA polyblends with increasing content of PMMA up to $7 \mathrm{wt} \%$ due to blending which strengthens the polyblends and also indicated by the value of $H_{\mathrm{v}}$ at $0 \mathrm{Mrad}$ is found to further strengthen with gamma radiation up to the lower dose range of $3 \mathrm{Mrad}$. This radiational hardening of blends is due to crosslinking between the two polymers. This crosslinking increases with dose up to $3 \mathrm{Mrad}$ as well as with increasing content of PMMA in the blends. PMMA is known to be a typical degradable polymer (Charlesby and Ross 1954) and its main chain suffers random degradation as a result of exposure to irradiation. However, some evidence of crosslinking in the blends of PMMA and some other polymers is available in literature (Wang et al 1989; Zhang et al 1991). Hence, the above results of PVF : PMMA blends are also suggestive of occurrence of radiation-induced crosslinking. The lower dose level range for this hardening character in the polyblends increases with PMMA content as observed to be 10 and $15 \mathrm{Mrad}$ for 5 and $7 \mathrm{wt} \%$ PMMA polyblends, respectively. Ano- 
ther remarkable fact observed for the radiational hardening for all the studied PVF : PMMA polyblends is that the maximum microhardness is found at the dose of $15 \mathrm{Mrad}$. This is the dose level at which density of developed crosslinks in the PVF : PMMA polyblends is the highest. Irradiation of these specimens at higher doses, i.e. beyond $15 \mathrm{Mrad}$, destroys these crosslinks in the blends as the degradative effect of PMMA starts dominating in the polyblends. This feature also receives support from the fact that the radiational degradation is more prominent in the polyblends with slightly higher PMMA content, i.e. for 5 and $7 \mathrm{wt} \%$ specimens. The slight decrease in the value of $H_{\mathrm{v}}$ between the dose range of 3 and $10 \mathrm{Mrad}$ is attributed to loosening of the crosslinks developed at $3 \mathrm{Mrad}$, hence softening of polyblends. The stronger crosslinks are developed at the dose of $15 \mathrm{Mrad}$ providing hardened blends. The degradative effect beyond $15 \mathrm{Mrad}$ is an outcome of molecular chain scissioning of the polymeric molecules which reduces the average molecular weight of the blended system (Bradley 1984), consequently, $H_{\mathrm{v}}$ decreases. The slight increase in the value of $H_{\mathrm{v}}$ between 20 and $30 \mathrm{Mrad}$ for polyblends with 1 and $3 \mathrm{wt} \%$ PMMA seems to be only superficial effect on these specimens.

\subsection{Effect of electron irradiation}

Figure 3 illustrates the variation of $H_{\mathrm{v}}$ with electron irradiation dose at the load of $60 \mathrm{~g}$ for pure PVF and different PVF : PMMA blend specimens. For pure PVF specimens $(100: 0)$, initially, $H_{\mathrm{v}}$ increases with increasing dose of electron irradiation in the lower dose range of 0 to $2 \mathrm{Mrad}$, indicating a clear evidence of radiational hardening due to crosslinking of PVF chains. Beyond 2 Mrad, $H_{\mathrm{v}}$ value decreases gradually to a small extent up to the dose level of $7 \mathrm{Mrad}$; however, these values are still higher than the unirradiated PVF specimens (0 Mrad). Finally, the microhardness of PVF specimens again shows an increasing trend beyond $7 \mathrm{Mrad}$ and exhibits maximum $H_{\mathrm{v}}$ value at $8 \mathrm{Mrad}$. It may, therefore, be concluded from the above observations that, in general, pure PVF specimens exhibit radiational crosslinking when exposed to electron irradiation and gets hardened. The decreasing trend in the value of $H_{\mathrm{v}}$ in the dose range of 2 to $7 \mathrm{Mrad}$, is attributed to the loosening of crosslinks; however, this effect is still contributory for the hardening of specimens due to radiation when compared to the unirradiated specimens. It is only the degree of crosslinks which varies. The maximum crosslinking is observed at $8 \mathrm{Mrad}$. Pure PVF is, therefore, a polymer which is conducive for radiational crosslinking in the specified dose of irradiation.

The $H_{\mathrm{v}}$-dose profile varies with the composition of the blend specimen. Initially, the value of $H_{\mathrm{v}}$ increases with electron irradiation dose up to $2 \mathrm{Mrad}$ for the blend specimens of 1 and $3 \mathrm{wt} \%$ of PMMA. The value of $H_{\mathrm{v}}$ for these specimens are greater than those of the unirradiated specimens $(0 \mathrm{Mrad})$. However, $H_{\mathrm{v}}$ decreases with the dose beyond $2 \mathrm{Mrad}$ and this decrease continues up to $7 \mathrm{Mrad}$ for these two blend specimens. Moreover, value of $H_{\mathrm{v}}$ is higher for $1 \mathrm{wt} \%$ of PMMA blend specimens as compared to the unirradiated ones. Thus specimens with $1 \mathrm{wt} \%$ of PMMA exhibits crosslinking due to electron irradiation at all the doses. However, the degree of crosslinking changes with the dose. Similar profile is obtained for the pure PVF (100: 0) specimens. However, the value of $H_{\mathrm{v}}$ for these specimens is less as compared to the blend with $1 \mathrm{wt} \%$ PMMA. Similarly, radiation crosslinking is also observed for $3 \mathrm{wt} \%$ PMMA specimens up to 2 Mrad. However, beyond this dose the degradation effect is observed up to the dose of $7 \mathrm{Mrad}$. Further, crosslinking predominates at $8 \mathrm{Mrad}$ and thereafter, scissioning is found to occur. Thus the polyblend of PVF : PMMA with $1 \mathrm{wt} \%$ PMMA exhibits radiational crosslinking and hardened blends are produced when specimens are exposed to electron radiation. This feature is attainable in the polyblends with $3 \mathrm{wt} \%$ PMMA only at 2 and $8 \mathrm{Mrad}$, at the other doses it is the degradative effect which is observed as the $H_{\mathrm{v}}$ values of irradiated specimens are less than the corresponding unirradiated polyblends.

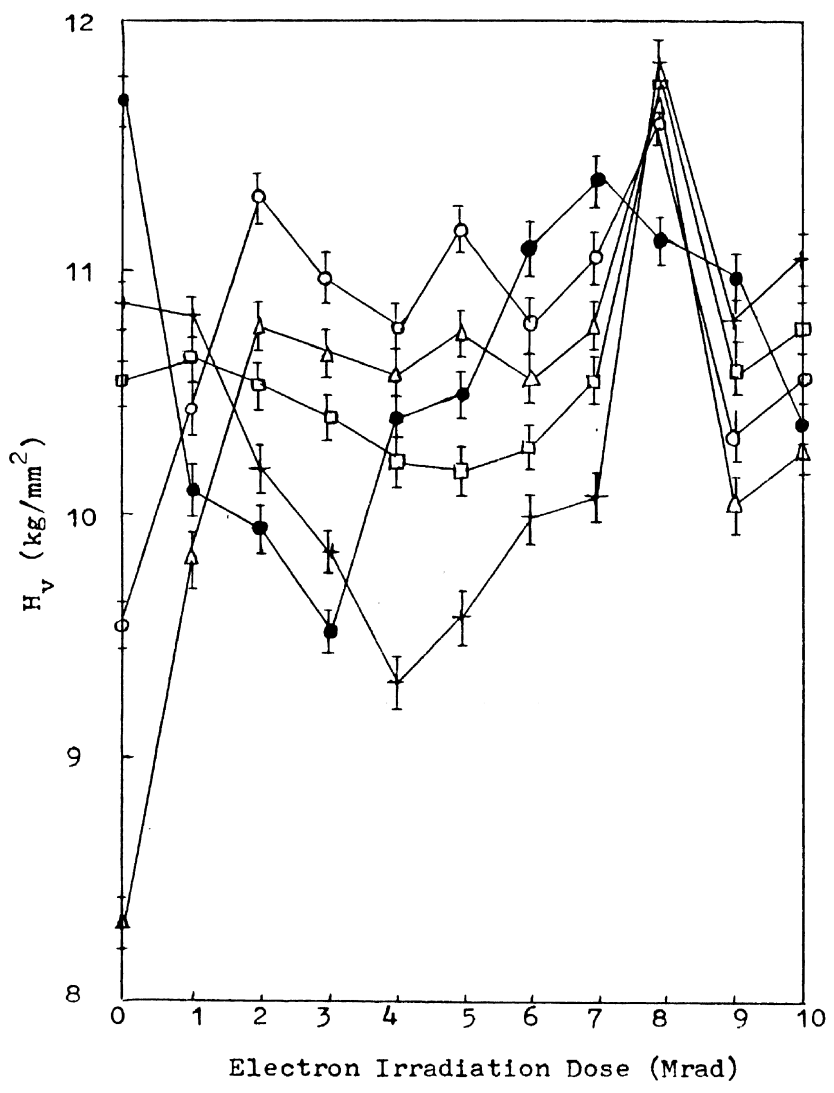

Figure 3. Variation of $H_{\mathrm{v}}$ with various doses of electron irradiation at a saturation load of $60 \mathrm{~g}$ for pure PVF and blend specimens of PVF : PMMA with different weight percentage ratios $(\Delta, 100: 0 ; 0,99: 1 ; \square, 97: 3 ;+, 95: 5$ and $\bullet, 93: 7)$. 
In polyblend specimens with 5 and $7 \mathrm{wt} \%$ of PMMA, the effect of electron irradiation is degradative up to the dose of $7 \mathrm{Mrad}$. These blend specimens get softened with irradiation as the scissioning process predominates in the polyblend system. However, slight increasing trend in the value of $H_{\mathrm{v}}$ beyond $4 \mathrm{Mrad}$ and maximum at $8 \mathrm{Mrad}$ for the blends with $5 \mathrm{wt} \%$ PMMA specimen indicates progressive crosslinking and radiational crosslinking is achievable at the dose of $8 \mathrm{Mrad}$ as the value of $H_{\mathrm{v}}$ at this dose is higher than the unirradiated polyblends. For $7 \mathrm{wt} \%$ PMMA blend specimens also the increasing value of $H_{\mathrm{v}}$ beyond $3 \mathrm{Mrad}$ and up to $8 \mathrm{Mrad}$ reveals slight crosslinking; however, these values are still smaller than the unirradiated ones and hence the electron radiation imparts overall softening effect to these polyblend specimens. Hence, the electron irradiation has deleterious effect on 93: 7 polyblends. PMMA exhibits crosslinking with PVF when exposed to electron radiation at lower concentration, i.e. $1 \mathrm{wt} \%$ PMMA at the dose range of 0 to $8 \mathrm{Mrad}$ only at the higher dose of $8 \mathrm{Mrad}$ for 3 and $5 \mathrm{wt} \%$ PMMA polyblends. This also seems true from the fact that PMMA is a degradative polymer (Charlesby and Ross 1954) and when this polymer is added to PVF in moderately higher concentration, i.e. 5 and $7 \mathrm{wt} \%$, then the polyblend so developed reverses its effect from radiational crosslinking observed for the lower content ( 1 and $3 \mathrm{wt} \%$ ) PMMA blends to radiational softening.

The degree of crosslinking in PVF : PMMA polyblends under gamma radiation seems to be more than under electron radiation as the level of radiational hardening observed is more in the case of gamma radiation. Further, the increasing trend of $H_{\mathrm{v}}$ values with increasing content of PMMA in the polyblend up to $7 \mathrm{wt} \%$ observed for the unirradiated (0 Mrad) specimens normally seems to be unaltered with gamma radiation dose up to $10 \mathrm{Mrad}$. This feature, however, gets reversed with electron radiation, where $H_{\mathrm{v}}$ values of the blends decrease with increasing content of PMMA. In the present investigation the electron irradiation is faster and its effect is, therefore, quicker and hence the degradation process predominates in PVF : PMMA polyblends whereas gamma irradiation provides sufficient time for crosslinking process to predominate.

\section{References}

Agrawal Pragyesh, Bajpai R and Datt S C 1996 Indian J. Pure Appl. Phys. 34780

Bajpai R, Mishra V and Datt S C 1992 Polym. Test. 11387

Bajpai R, Agrawal Pragyesh and Datt S C 1994 Polym. Int. 34 249

Bajpai R, Mishra V, Agrawal P and Datt S C 2002 Bull. Mater. Sci. 2521

Bopp C D and Sisman O 1955 Nucleonics 1328

Bradley R 1984 Radiation technology handbook (New York and Basel: Marcel Dekker) p. 74

Charlesby A 1954 Proc. R. Soc. A224 120

Charlesby A and Ross M 1954 Proc. R. Soc. A223 393

Gonzalez A, Martin G J, De Saja J A and Rodriguez R 1986 J. Appl. Polym. Sci. 31717

Hermes H E and Higgins J S 1998 Polym. Eng. Sci. 38 847

Hu J, Schulze U and Pionteck J 1999 Polymer 405279

Jarvis N L, Fox R B and Zisman W A 1964 Adv. Chem. Ser. (Washington DC: ACS) p. 317

McCarthy D W and Mark J E 1998 Rubber Chem. Technol. 71 941

Mishra V, Bajpai R and Datt S C 1994 Polym. Test. 13435

Nagesh N, Dokhale P A and Bhoraskar V N 1999 J. Phys. D: Appl. Phys. 321189

Pandey S, Bajpai R and Datt S C 1990 Polym. Test. 10111

Sisman O and Bopp C D 1954 ORNL 928

Wang H, Zhang W and Sun J 1989 J. Rad. Res. Rad. Proc. (China) 738

Zhang W, Wang H and Sun J 1991 J. Macromol. Sci. Phys. B30 41 